\title{
Interested, Disinterested, or Neutral: Exploring STEM Interest Profiles and Pathways in A Low-Income Urban Community
}

\author{
Nancy L Staus ${ }^{1 *}$, John H Falk ${ }^{1}$, William Penuel ${ }^{2}$, Lynn Dierking ${ }^{1}$, Jennifer Wyld ${ }^{1}$, Deborah Bailey ${ }^{3}$ \\ 1 Oregon State University, USA \\ 2 University of Colorado Boulder, USA \\ ${ }^{3}$ Oregon Department of Education, USA
}

Received 7 October 2019 - Accepted 30 March 2020

\begin{abstract}
To better understand STEM interest development during adolescence in an urban community, we examined how "STEM Interested" youth differed from disinterested youth and how interest changed over time from age $11 / 12$ to $12 / 13$. We surveyed youth to measure interest in four components of STEM, used cluster analysis to categorize youth based on STEM interest, and examined how interest profiles and pathways differed for several explanatory factors (e.g., parental support, gender). Three STEM interest profiles emerged from the analysis: Stem Interested, Math Disinterested, and STEM Disinterested. Only STEM Disinterested youth lost interest in science, technology/engineering, and mathematics while the remaining $76 \%$ of youth remained at least somewhat interested in science and technology/engineering. Girls were just as likely as boys to identify as STEM Interested. Participation in out-of-school STEM activities and positive parental attitudes toward science were significant predictors of persistent STEM interest. Decreases in STEM interest were associated with declines in science self-concept and perceived parental attitudes toward science. Results suggested that declining STEM interest may not be the norm for urban youth. The findings also revealed factors that may influence declining STEM interest and reinforced the importance of out-of-school factors in developing and sustaining STEM interest during adolescence.
\end{abstract}

Keywords: cluster analysis, STEM pipeline, STEM interest, STEM pathways

\section{INTRODUCTION}

Interest in STEM topics and disciplines declines over the years that youth are in school (for reviews, see Galton, 2009; Osborne, Simon, \& Collins, 2003; Potvin \& Hasni, 2014). Although young children report widespread interest in a variety of natural phenomena, including many STEM topics, this interest steadily declines through primary and secondary school with enduring interest in STEM being largely formed by age 13/14 (Lindahl, 2007; Ormerod \& Duckworth, 1975; Tai, Liu, Maltese, \& Fan, 2006). This pattern tends to be most pronounced for girls, non-white ethnic minorities, and urban low-income youth who report less positive attitudes about science, participate in fewer relevant outof-school activities, and are less likely to pursue further study and careers in STEM (Baram-Tsabari \& Yarden, 2008; Basu \& Barton, 2007; Breakwell \& Beardsell, 1992; Campbell, Denes, \& Morrison, 2000, DeWitt et al., 2011; Frenzel, Goetz, Pekrun, \& Watt, 2010; Gilmartin, Li, \& Aschbacher, 2006; Taylor, 1993).

The above statements are part of the well-known story of the leaky STEM pipeline in which adolescent youth lose interest in STEM culminating in fewer youth taking STEM coursework in high school and fewer still choosing to major in scientific fields. Although each piece is supported by research, it is an incomplete story about who maintains or loses interest in STEM topics or disciplines during adolescence-and potential reasons for these different STEM interest pathways - for several reasons. First, we actually know very little about the nature of interest in multiple components of STEM 


\section{Contribution to the literature}

- Measures and tracks four components of STEM interest simultaneously over time to detect patterns of STEM interest and factors that influence them.

- Introduces an innovative methodology in which youth are segmented based on STEM interest profiles to examine how "STEM interested" youth differ from those who lose interest over time. This method avoids adverse issues related to a priori classification schemes (e.g., gender or ethnicity) or treating youth as a homogeneous group (e.g., reporting average changes only).

- Contributes to knowledge about why some youth may lose interest in STEM during adolescence, an under-researched area of this long-standing issue in science education.

during adolescence. The majority of research in this area has focused on attitudes toward or interest in science as a general concept or on a single STEM topic or school subject (e.g., math, physics), rather than examining changes in interest across multiple components of STEM simultaneously (e.g., Frenzel et al., 2010; Häussler \& Hoffmann, 2002; Krogh \& Thomsen, 2005; Salta \& Tzougraki, 2004).

Second, most research has been cross-sectional in nature, comparing different youth at one point in time, making it difficult to examine youth STEM interest pathways over time and the factors that influence them (e.g., Osborne et al., 2003; Sjøberg \& Schriener, 2010).

Third, a large body of STEM interest research focuses on demographic differences (e.g., girls compared to boys) which does not adequately address the diversity within these groups and may exaggerate differences leading to stereotypes that "fit no one in particular" (Brickhouse, Lowery, \& Schultz, 2000, p. 442).

Finally, although several researchers have examined the factors associated with the development and maintenance of STEM attitudes or interest over time (Maltese, Melki, \& Wiebke, 2014), little is known of what factors are most important in explaining the decline in STEM interest during adolescence that has been observed in many Western countries (Osborne et al., 2003, Potvin \& Hasni, 2014).

In order to address these issues and contribute to the collective understanding of STEM interest development during adolescence, particularly in low-income urban communities, our longitudinal study of middle school youth in a poor, under-resourced school district in Oregon, U.S.A. took a different approach. First, we measured youth interest in four components of STEM simultaneously each year (earth/space science, human biology, technology/engineering, and mathematics) so we could track changes in interest over time for each dimension. Second, we used cluster analysis to classify youth based on their STEM interest profiles and examined how associated factors such as participation in out-of-school STEM and parental support varied across profiles. Finally, we examined changes in STEM interest for youth in each profile over time and compared how youth who remained "STEM interested" differed from those who became "STEM disinterested," for a variety of associated factors (e.g., parental support, demographics). By examining factors associated with declining interest during adolescence, we shed light on an under-researched area of a long-standing issue in science education that may inform interventions that minimize the decline in STEM interest for more adolescent youth.

\section{THEORETICAL FRAMEWORK}

It is becoming increasingly clear that affective and socioemotional factors including attitudes, interest, and motivation are critically important in the learning process (Fortus, 2014; Maltese et al., 2014; Maltese \& Tai, 2011; Vedder-Weiss \& Fortus, 2011). STEM interest in particular is a motivational variable directly linked to participation in related activities. That is, youth who are interested in STEM are very likely to seek out and engage with STEM-related content and activities both in- and out-of-school (Renninger \& Hidi, 2011; Renninger \& Riley, 2013). Substantial research indicates that interest in STEM during adolescence is a key factor in persistence; a significant number of students who major in STEM disciplines make that choice by high school on the basis of interest rather than achievement (Maltese et al. 2014; Maltese \& Tai, 2011; Tai, Liu, Maltese, \& Fan, 2006). Therefore, interest in STEM content and activities during adolescence may be a significant predictor of future engagement in STEM activities or careers.

\section{Perspectives on STEM}

A problematic issue for educators and researchers is the lack of a common interpretation of STEM which has been defined variously as four separate disciplines or as the integration of the disciplines into a larger whole (Burke, Frances, \& Shanahan, 2014; English, 2017; Morrison, 2006). Although we recognize that STEM is often conceptualized as a meta-discipline that can be used to solve complex problems, in practice most schools continue to teach STEM disciplines as separate classes (e.g., math, science; National Research Council, 2011). In addition, youth interest is often specific to a subject area rather than a STEM domain (Krapp, 2002). Therefore, we chose to measure youth interest in each of the separate disciplines that make up the larger construct of STEM. 


\section{Conceptualizations of STEM Interest}

Our conceptualization of interest was guided by Hidi and Renninger's (2006) Four-Phase Model of Interest which describes the progression of interest development towards a consistent and internalized interest in a topic or activity. In this model, early "situational interest" is triggered by an event in a learner's environment that captures his/her attention for a short time. If this situational interest is maintained through repeated engagement and external motivations (e.g., encouragement from parents or teachers), it could progress to an emerging individual interest and finally a well-developed individual interest characterized by selfregulated and independent learning along with increased knowledge and value for the topic or activity of interest (Hidi \& Renninger, 2006; Renninger \& Su, 2012). Individual interest, because it is self-driven, is more likely to endure over time, potentially affecting later school and career choices. However, very few situational interests become individual interests. Our study aimed to better understand the factors that support development of individual interest in STEM, as well as those that do not, in order to inform educational interventions that may help youth develop strong, enduring interest in STEM.

Our study also was informed by the Person-object Theory of Interest (Krapp, 2002) which proposes that interest is always specific to a certain content or activity. In particular, STEM interest appears to be topic rather than domain specific such that learners may develop a strong interest in a specific subject area (e.g., electricity) while reporting low interest in the corresponding science domain (i.e., physics; Häussler \& Hoffmann, 2000; Krapp \& Prenzel, 2011). There appears to be a gendered aspect to STEM interest as well with girls reporting greater interest than boys in the life sciences while boys showed more interest in physics and chemistry subject areas (Häussler \& Hoffmann, 2000). Similarly, Sjøberg and Schreiner (2010) found that science and technology interests were highly context-dependent based on gender and that this pattern held for youth in a variety of different countries. These findings strongly informed our survey development in which we avoided using broad domain terms such as "science" or "technology" in favor of including a variety of subject-specific topics and activities of interest to both boys and girls.

\section{Potential Influences on STEM Interest}

There are a number of potentially powerful influences which are critical to understanding the pathways of STEM interest development during adolescence. For example, participation in out-of-school STEM activities such as watching STEM-related TV shows or attending science clubs may critically support learners' pursuit of lifelong STEM interests and understandings, both in and out of school (cf., Barron,
2006; Bevan et al., 2010; Falk \& Dierking, 2002, 2010; Falk \& Needham, 2013; National Research Council, 2015; Stocklmayer, Rennie \& Gilbert, 2010).

Other research has emphasized the importance of school or classroom context in supporting youth STEM interest over time. For example, Myers and Fouts (1992) showed that students reported more positive attitudes in classrooms with more supportive and innovative teachers. Vedder-Weiss and Fortus (2011) found significantly higher motivation to learn science for youth attending democratic schools (where youth had greater choice and autonomy) compared to youth in traditional schools. Similarly, DeWitt and colleagues (2013) found that the school a child attended was significantly related to the child's future science aspirations.

Parents are also important for the development of STEM interests in youth. For example, parental attitudes toward science, as well as parental encouragement and support for youth interests, seems to play a strong role in youth's developing interest in science and math studies and careers (Archer et al., 2012; Dunst \& Raab, 2006; Ferry, Fouad, \& Smith, 2000; Frenzel et al., 2010; Gilmartin, Li, \& Aschbacher, 2006; Harackiewicz, Rozek, Hulleman, \& Hyde, 2012; Maltese et al., 2014).

Finally, aspirations for the future are closely related to interest and can greatly influence children's eventual decisions about what to major in and what career they eventually choose (DeWitt et al., 2011; Lindahl, 2007; Tai et al., 2006).

\section{Profiles of Youth STEM Interests}

The majority of studies considering youth interest in or attitudes toward science or STEM have examined samples of students as a whole or documented associations with demographic variables such as gender or ethnicity, making the implicit assumption that these groups of youth are homogeneous in terms of STEM interest (Osborne et al., 2003). More recently researchers have sought to identify distinct profiles of youth for a variety of constructs such as subjective task values (Chow, Eccles, \& Salmela-Aro, 2012), expectancy-value motivation (Andersen \& Chen, 2016) and utility and selfconcept beliefs (Sheldrake, Mujtaba, \& Reiss, 2019), and investigate the associations between profile membership and a variety of explanatory factors (e.g., gender, aspirations). However, no studies to date have examined profiles based on STEM interest or documented associated STEM interest pathways over time. Considering profiles of STEM interest could help quantify proportions of youth who are interested or disinterested in STEM and how these groups differ in terms of demographic, personal and environmental variables. Examining changes in interest over time for each profile and associated variables will provide a more nuanced understanding of STEM interest, why it may 
decline and how it can be better supported during adolescence.

\section{RESEARCH QUESTIONS}

The Synergies project was designed to investigate and understand the STEM interest profiles and associated pathways of a cohort of low-income adolescents as they progressed from ages 11/12 (sixth grade) through ages $13 / 14$ (eighth grade) in an underserved community in Oregon, U.S.A. Data were collected using both a survey administered once yearly and bimonthly interviews with case study youth and their parents. In this paper we report survey results in which we explored STEM interest patterns for youth between ages 11/12 (sixth grade) and 12/13 (seventh grade) in order to address the following questions:

(1) What is the nature of the STEM interest profiles of adolescent youth in an urban community and how do associated factors (e.g., parental support, participation in out-of-school STEM) vary across profiles?

(2) What are the STEM interest pathways of these youth between ages 11/12 (sixth grade) and 12/13 (seventh grade), and how do they compare to the pathway of sampled youth overall?

(3) What factors are associated with maintaining or declining STEM interest over time?

\section{METHODS}

\section{Survey Instrument}

A goal of the Synergies Project was to develop a selfreporting instrument that measured interest in each of the subdisciplines that make up the larger construct of STEM which would allow us to examine patterns of STEM interest over time. In addition, we included items and constructs that measured a variety of factors known to influence STEM interest development as described above (e.g., parental support, participation in out-ofschool STEM activities). A complete discussion of survey development and validation is available elsewhere (Falk, Staus, Dierking, Penuel, Wyld, \& Bailey, 2016; Staus, Lesseig, Lamb, Falk, \& Dierking, 2019); we provide a brief summary of the process here.

The questionnaire instrument was developed using an iterative, construct-centered process which drew on existing instruments including science interest items from the ASPIRE survey (DeWitt et al., 2011) and ROSE Questionnaire (Schreiner \& Sjøberg, 2004), and a large body of research on interest development and the personal and environmental factors that affect interest (as discussed above). To further increase validity, the survey items were reviewed by five internationally recognized experts on STEM interest and piloted in a community similar to the study site.
Because of the topic-specific nature of STEM interest (Krapp \& Prenzel, 2011), we avoided the use of domainlevel terms such as "science" or "engineering" when developing survey items. Instead, we focused on youthcentered activities and/or practices related to STEM that youth in the community would recognize and have opportunities in which to engage. We purposely narrowed our content focus to areas that youth were likely to encounter in school (e.g., earth sciences) and out of school (e.g., consumer technology) and included items known to appeal to both boys and girls. For example, rather than asking youth if they were interested in "science," we asked about specific science-related topics that were familiar to this group of youth (e.g., aspects of space exploration). Although we included a broad range of STEM topics, it was not possible to include an exhaustive list due to survey length constraints. However, topics we did not cover (e.g., physics) were unlikely to be encountered by this population of youth. See Appendix for component items and corresponding Cronbach's alphas.

The initial version of our survey instrument was pilot-tested with 257 youth of ages 10-14, and principal components analysis and measures of internal consistency (i.e., Cronbach's alpha) were conducted to establish psychometric validity and refine the items and scales. Removal of items with factor loadings under 0.5 or that lowered the reliability of the scale resulted in a sixteen item STEM interest measure, three to five interest items per content construct (see Appendix). Four components of STEM interest emerged from the PCA which were identifiable as earth/space science, life science, technology/engineering, and mathematics. The validity and reliability of these items were subsequently confirmed with 811 youth in a nearby community through a Structural Equation Model consisting of a path analysis and confirmatory factor analysis, and through comparison with instruments that measure science and mathematics interest specifically (Status et al., 2019). We used these interest measures to track youth STEM interest pathways over time.

In addition, we included sixteen science interestassociated items adapted from the ASPIRE survey which factored into four constructs (DeWitt et al., 2011): science enjoyment, negative science self-concept, parental attitudes to science, and science relevance (See Appendix for component items and corresponding Cronbach's alphas). Although ideally we would have included measures for all components of STEM, survey length and time constraints required us to use "science" as a proxy for STEM in this case.

Other measures in the survey consisted of single items or indexes comprised of the mean of several items. "Science aspiration" was measured by a single item on a five-point scale ("I expect to become a scientist someday"). We included a measure of participation in out-of-school STEM activities ("STEM activities") based 
on the frequency with which youth participated in five activities that emerged from the pilot study as readily available to youth in this community: visiting the local science museum, gardening or growing plants, doing science kits or experiments, watching a TV program about STEM, and building or taking things apart or repairing things. Sunrise Middle School (pseudonym) does not use grades so our measure of "STEM knowledge" consisted of youth perceptions of their knowledge about 10 of the STEM interest items on the survey (see italicized items in Appendix). Finally, we measured support for STEM learning ("STEM helpparent, -teacher") by asking youth to indicate who helped them learn about each of the 10 items (youth could choose one person, both or neither). A copy of the questionnaire is available from the authors upon request.

\section{Participants}

Our project focused on a single middle school in a racially and ethnically diverse community within a metropolitan area in Oregon, USA, in which $79 \%$ of youth qualified for free or reduced-price lunch (U.S. index of poverty). The target audience was served by a single school district but was underserved in terms of availability of informal STEM institutions and organizations which generally were located outside of the community (e.g., science center, zoo, children's museum). We chose this community because it was large enough to mirror many of the complex dynamics of major urban areas, yet small enough to be manageable in both scope and scale.

All students at Sunrise Middle School were invited to participate in the study. The questionnaire was administered to all youth who returned a signed parental consent form. The number and make-up of the participants changed somewhat over time as youth entered or left the school district. The questionnaire was administered to 142 youth aged 11/12 (sixth grade) in the first year of the study, and 157 aged 12/13 (seventh grade) in the following year. A total of 106 youth participated in the survey as both 11/12 and 12/13-yearolds, allowing us to document these youth's STEM interest pathways and associated factors over time. More girls than boys participated in the survey, consistent with Sunrise population statistics (U.S. Census Bureau, 2012); the sample contained a higher percentage of Asian or Asian American youth and a lower percentage of white youth than the community at large based on 2012 census data (Table 1).

\section{Data Analysis}

In order to investigate the underlying patterns of STEM interest within the data, we used K-means cluster analysis on the four STEM interest components of youth aged 12/13 (earth/space science, life science,
Table 1. Demographic composition of the youth $(n=106)$ who participated in the survey as both $11 / 12$ (sixth grade) and 12/13-year-olds (seventh grade)

\begin{tabular}{lcc}
\hline Demographic category & Number of youth & Percentage \\
\hline $\begin{array}{l}\text { Gender } \\
\text { Male }\end{array}$ & 59 & $56(54)$ \\
$\begin{array}{l}\text { Ethnicity } \\
\text { Hispanic }\end{array}$ & 47 & $44(46)$ \\
$\quad$ Asian/Asian & 20 & $19(16)$ \\
American & 29 & $27(11)$ \\
$\quad$ White & 33 & $31(56)$ \\
$\quad$ African American & 14 & $13(15)$ \\
$\quad$ Other & 10 & $9(2)$ \\
\hline
\end{tabular}

Note: Numbers in parentheses represent national statistics from 2012 census figures (United States Census Bureau, 2012)

technology/engineering, mathematics) to segment the youth into STEM interest profiles, and examined how these groups' STEM interests changed between ages $11 / 12$ and 12/13. Cluster analysis identifies naturally occurring distinct groups of youth from the data who exhibit similar patterns of responses based on small within-group and large between-group variance, and therefore is a purely empirical method of classification requiring no a priori assumptions about the relationships within the data (Fouts, 1987; Gerard, 1957). $K$-means is one of the most efficient clustering methods and operates by optimizing the squared error function when partitioning data into similar groups or clusters (Jain \& Dubes, 1988). The groups may then be compared, through ANOVA, on the four STEM interest components as well as other variables not used in the clustering procedure (e.g., participation in out-of-school activities). We utilized the elbow method to determine the number of clusters in which the sum of squared errors is plotted against each value of $k$ (Kodinariya \& Makwana, 2013). The goal is to choose a small value of $k$ that still has a low SSE, and the elbow represents the point of diminishing returns by increasing $k$.

We calculated the interest profiles for 12/13-yearolds (rather than 11/12-year-olds) as this is the age group that has most likely formed stable, enduring interests in STEM and whose interest pathways we would like to better understand (Lindahl, 2007; Tai et al., 2006). We used one-way ANOVA to investigate how science enjoyment, science self-concept, parental attitudes to science, science relevance/value, STEM knowledge, science aspirations, STEM support from parents and teachers, science teacher, and participation in STEM activities differed among profiles and paired $t$ tests to examine changes over time. SPSS 22.0 software was used for all analyses.

Because the Bonferroni correction for multiple comparisons may greatly inflate the likelihood of making a Type II error while decreasing the probability of finding a significant result, particularly with small sample sizes (Moran, 2003; Wright, 1992), we followed the suggestion of Moran (2003) by reporting exact $p$ - 
Table 2. ANOVA of STEM component interest by STEM Interest Profile for all 12/13-year-old (seventh grade) youth participating in the survey

\begin{tabular}{lcccccc} 
& \multicolumn{4}{c}{ STEM Interest Profile } & & \\
\cline { 2 - 5 } STEM Interest & $\begin{array}{c}\text { STEM } \\
\text { Interested } \\
(\mathrm{n}=49)\end{array}$ & $\begin{array}{c}\text { Math } \\
\text { Disinterested } \\
(\mathrm{n}=68)\end{array}$ & $\begin{array}{c}\text { STEM } \\
\text { Disinterested } \\
(\mathrm{n}=38)\end{array}$ & F-value & $p$-value & Effect size eta \\
\hline Earth/space science & $4.42^{\mathrm{a}}$ & $3.68^{\mathrm{b}}$ & $2.71^{\mathrm{c}}$ & 80.99 & $<0.001$ & 0.72 \\
Life science & $4.24^{\mathrm{a}}$ & $3.43^{\mathrm{b}}$ & $2.54^{\mathrm{c}}$ & 65.98 & $<0.001$ & 0.68 \\
Technology/engineering & $4.31^{\mathrm{a}}$ & $3.32^{\mathrm{b}}$ & $2.38^{\mathrm{c}}$ & 123.36 & $<0.001$ & 0.79 \\
Mathematics & $3.98^{\mathrm{a}}$ & $2.94^{\mathrm{b}}$ & $1.81^{\mathrm{c}}$ & 128.82 & $<0.001$ & 0.79 \\
\hline
\end{tabular}

Note: Means with different superscripts are significant at $p<0.05$ based on Scheffe post-hoc tests for equal variances. STEM interest measures range from $1=$ "Not interested" to $5=$ "Very interested."

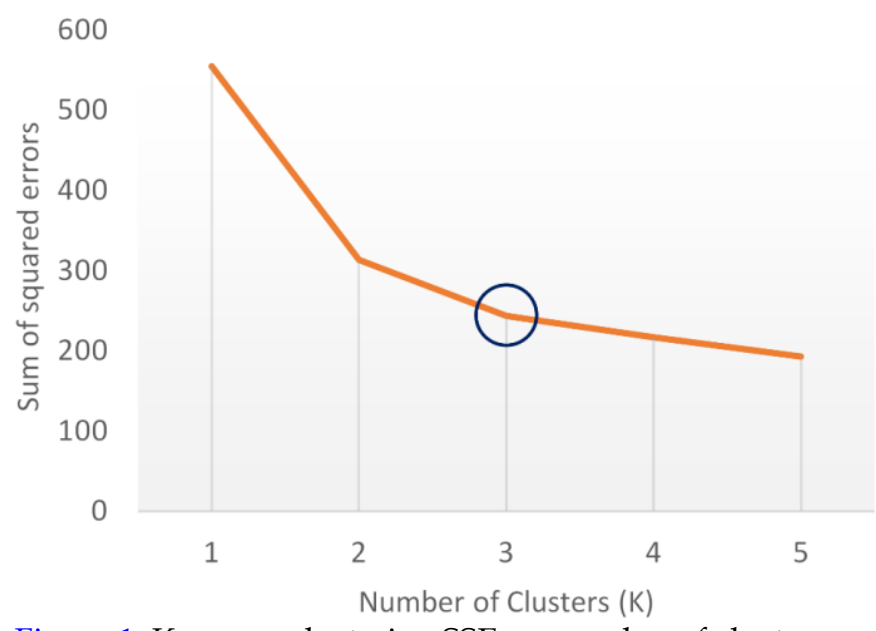

Figure 1. K-means clustering SSE vs. number of clusters

values along with effects sizes to allow readers to make reasonable interpretations of the results.

\section{FINDINGS}

\section{STEM Interest Profiles and Associated Factors}

To answer the first research question, we conducted a cluster analysis using the scores from the four STEM interest components. Three distinct STEM interest profiles emerged for all youth who completed the survey as 12/13-year-olds, which we identified as "STEM interested,", "Math disinterested,", and "STEM disinterested" (Figure 1). Youth in each profile differed significantly for all four STEM interest components with large effect sizes (Table 2), further validating the choice of three groups. The STEM Interested profile made up $32 \%$ of the sample $(n=49 ; 22$ girls $)$ and was characterized by significantly greater interest in all four STEM components than youth in the other profiles. Youth in the Math Disinterested profile made up $44 \%$ of the sample ( $\mathrm{n}=68 ; 47$ girls) and reported slightly positive interest in earth/space science, life science, and technology/engineering, but slightly negative interest in math. Youth in the STEM Disinterested profile comprised $24 \%$ of the sample $(n=38 ; 20$ girls) and stood apart as the group with the lowest interest in all four STEM components. Although there were no gender differences within the STEM Interested and STEM Disinterested groups, girls were more likely than boys to identify with the Math Disinterested group $(\chi=7.82$, $p=0.020)$; specifically, $53 \%$ of girls identified with the Math Disinterested group compared to $31 \%$ of boys. Due to our small sample size, we were unable to investigate differences among STEM interest profiles based on race/ethnicity.

Next, we examined how the associated personal and environmental factors varied across the three interest profiles and found that youth in each profile differed in several important ways (Table 3). For example, youth who were STEM Interested enjoyed science more and

Table 3. Relation of interest-related factors to STEM Interest Profiles for all 12/13 year old youth

\begin{tabular}{|c|c|c|c|c|c|c|}
\hline \multirow[b]{2}{*}{$\begin{array}{l}\text { Personal and Environmental } \\
\text { Factors }\end{array}$} & \multicolumn{3}{|c|}{ STEM Interest Profile ${ }^{1}$} & \multirow[b]{2}{*}{ F-value } & \multirow[b]{2}{*}{$p$-value } & \multirow[b]{2}{*}{$\begin{array}{c}\text { Effect size } \\
\text { eta }\end{array}$} \\
\hline & $\begin{array}{c}\text { STEM } \\
\text { Interested } \\
(\mathrm{n}=49)\end{array}$ & $\begin{array}{l}\text { Math Disinterested } \\
\qquad(\mathrm{n}=68)\end{array}$ & $\begin{array}{c}\text { STEM } \\
\text { Disinterested } \\
(n=38)\end{array}$ & & & \\
\hline $\begin{array}{l}\text { Science self-concept (negative) }{ }^{2} \\
\end{array}$ & 2.73 & 3.00 & 3.03 & 1.14 & 0.321 & 0.15 \\
\hline Parent science attitude ${ }^{2}$ & $3.27 \mathrm{a}$ & $2.92^{\mathrm{a}}$ & $2.30^{b}$ & 9.84 & $<.001$ & 0.36 \\
\hline Science relevancy ${ }^{2}$ & $4.02^{\mathrm{a}}$ & $3.52^{\mathrm{b}}$ & $3.10^{\mathrm{b}}$ & 11.44 & $<.001$ & 0.38 \\
\hline Science enjoyment ${ }^{2}$ & $4.04^{\mathrm{a}}$ & $3.24^{\mathrm{b}}$ & $2.86^{\mathrm{b}}$ & 14.16 & $<.001$ & 0.42 \\
\hline STEM activities ${ }^{3}$ & $2.78^{a}$ & $2.17 \mathrm{~b}$ & $1.95^{b}$ & 11.39 & $<.001$ & 0.40 \\
\hline STEM knowledge 4 & $2.78^{a}$ & $2.63 \mathrm{ab}$ & $2.48^{\mathrm{b}}$ & 5.34 & 0.006 & 0.27 \\
\hline STEM help - parent ${ }^{5}$ & 0.23 & 0.26 & 0.18 & 1.82 & 0.166 & 0.16 \\
\hline STEM help - teacher 5 & 0.47 & 0.48 & 0.48 & 0.05 & 0.951 & 0.07 \\
\hline Science aspirations ${ }^{2}$ & $2.60^{a}$ & $2.06^{b}$ & $1.42^{c}$ & 12.83 & $<.001$ & 0.38 \\
\hline
\end{tabular}

Note: 1Profile means with different superscripts are significantly different at $p<0.05$ based on Tamhane's post-hoc tests for unequal variances; ' $I$ tems in each index were coded on a five-point scale from $1={ }^{\prime}$ Disagree a lot' to $5={ }^{\prime}$ Agree a lot.'; ${ }^{3}$ Items were coded on a five-point scale from $1={ }^{\prime}$ Hardly ever or never' to $5={ }^{\prime}$ Almost every day.'; ${ }^{4}$ Items were coded on a four-point scale from

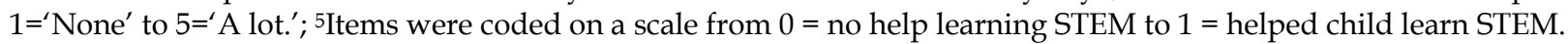


Table 4. Comparison of STEM interests between 11/12 (sixth grade) and 12/13-year-old (seventh grade) youth (n=106) and by gender

\begin{tabular}{|c|c|c|c|c|c|c|c|}
\hline \multirow{2}{*}{ STEM Interest } & \multicolumn{2}{|c|}{ 11/12-yr-old } & \multicolumn{2}{|c|}{ 12/13-yr-old } & \multirow{2}{*}{$t$-value } & \multirow{2}{*}{$p$-value } & \multirow{2}{*}{ Cohen's $d$} \\
\hline & Mean & SE & Mean & SE & & & \\
\hline \multicolumn{8}{|c|}{ Earth/space science } \\
\hline All & 3.96 & 0.08 & 3.75 & 0.09 & 2.89 & 0.005 & 0.44 \\
\hline Girls & 3.96 & 0.09 & 3.67 & 0.11 & 3.03 & 0.004 & 0.34 \\
\hline Boys & 3.92 & 0.13 & 3.84 & 0.13 & 0.77 & 0.445 & 0.09 \\
\hline \multicolumn{8}{|l|}{ Life science } \\
\hline All & 3.72 & 0.10 & 3.45 & 0.09 & 2.35 & 0.021 & 0.28 \\
\hline Girls & 3.79 & 0.12 & 3.62 & 0.10 & 1.14 & 0.259 & 0.19 \\
\hline Boys & 3.62 & 0.15 & 3.24 & 0.15 & 2.25 & 0.030 & 0.38 \\
\hline \multicolumn{8}{|c|}{ Tech/engineering } \\
\hline All & 3.62 & 0.08 & 3.47 & 0.09 & 1.51 & 0.134 & 0.18 \\
\hline Girls & 3.48 & 0.11 & 3.28 & 0.11 & 1.50 & 0.138 & 0.24 \\
\hline Boys & 3.80 & 0.12 & 3.72 & 0.13 & 0.55 & 0.585 & 0.09 \\
\hline \multicolumn{8}{|l|}{ Mathematics } \\
\hline All & 3.26 & 0.09 & 2.98 & 0.10 & 2.71 & 0.008 & 0.28 \\
\hline Girls & 3.15 & 0.12 & 2.85 & 0.12 & 2.11 & 0.040 & 0.31 \\
\hline Boys & 3.40 & 0.14 & 3.14 & 0.17 & 1.68 & 0.099 & 0.25 \\
\hline
\end{tabular}

Note: Interest coded on a five-point scale from $1={ }^{\prime \prime}$ Not interested" to $5=$ "Very interested." Girls $n=59$; boys $n=47$.

found it significantly more relevant to their lives than youth in the other profiles. In addition, youth in that profile engaged in significantly more STEM-related outof-school activities such as doing science experiments/kits, gardening, watching STEM-related TV shows, and building things than those in the other two profiles, with large effect sizes. They also reported being more knowledgeable about STEM topics than youth in the STEM Disinterested profile.

In contrast, youth who were STEM Disinterested reported that their parents had significantly lower positive attitudes toward science than youth in the other two groups. Interestingly, there were no differences in science self-concept among profiles. In other words, those who were disinterested in STEM did not perceive science as being significantly more difficult for them than those who were interested in STEM. In addition, there were no differences among interest profiles in the amount of support youth received from parents or teachers in learning about STEM. We also found no difference in STEM interest profiles based on science teacher effect $(\chi=6.518, p=0.368)$. Finally, although youth in the STEM Interested profile were significantly more likely to agree with the item "I expect to become a scientist someday," their science aspirations were in fact negative (2.6 on a 5-point scale). That is, even youth in our sample who reported a strong interest in STEM did not endorse the idea that they would become a scientist in the future.

\section{STEM Interest Pathways}

To answer the second research question, we examined how STEM interest changed over time first for the sample as a whole and then for youth in the three interest profiles. Overall, sampled youth exhibited the typical pattern of declining interest in three of the four STEM domains we measured: earth/space science, human biology, and math. There was no change in technology/engineering interest during this time (Table 4). However, this was not the case for youth in two of the three STEM interest profiles (Figure 2). In fact, youth in the STEM Interested profile reported a significant increase in interest in technology/engineering and no change in interest for the other three components. Similarly, youth in the Math Disinterested profile reported no significant changes in interest for any of the four STEM components between ages 11/12 and 12/13. Only youth in the STEM Disinterested profile indicated significant declining interest in all four STEM components. In other words, for $76 \%$ of $12 / 13$-year-olds who also took the survey as 11/12-year-olds, STEM interest remained the same or increased over time.

\section{Factors Associated with STEM Interest Pathways}

In order to answer research question three regarding specific factors associated with the maintenance of STEM interest as well as the decline in STEM interest over time, we investigated how four of the most significant interestrelated factors changed between ages 11/12 and 12/13 for youth in each STEM interest profile. Youth in the STEM Interested and Math Disinterested profiles who maintained at least a moderate interest in STEM over time reported no changes in parental attitudes toward science, science self-concept, participation in STEM activities, or future science aspirations (Table 5). However, youth in the STEM Disinterested profile who reported a significant decline in STEM interest over time, also exhibited significant decreases in a number of associated factors including science self-concept, parental attitudes toward science, and science aspirations between sixth and seventh grade. 

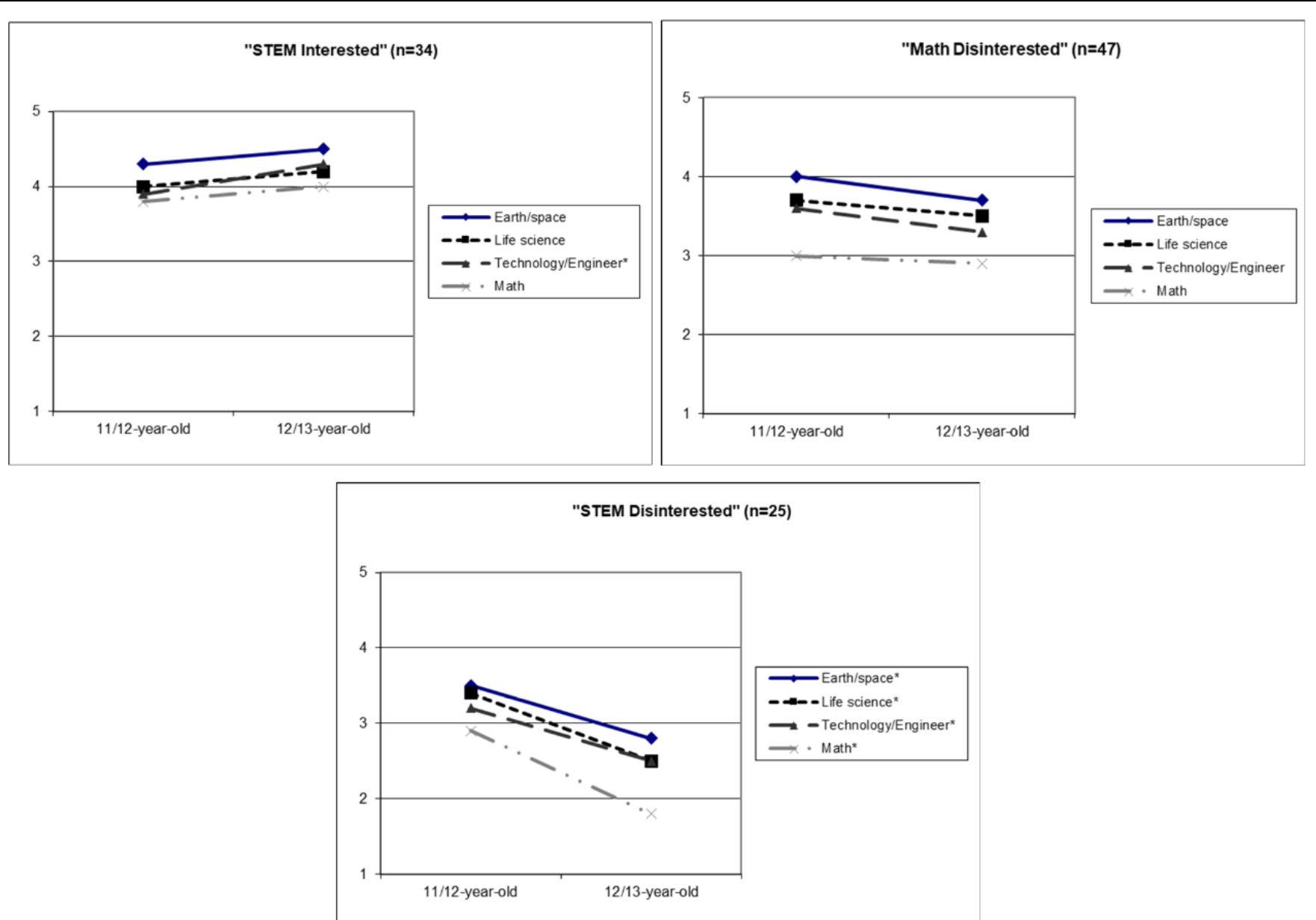

Figure 2. STEM interest pathways for youth who participated at both 11/12 (sixth grade) and 12/13 (seventh grade) years old by STEM Interest Profile. Interest scores ranged from $1=$ "Not interested" to $5=$ "Very interested." Pathways with an asterisk denote significant differences at the $\mathrm{p}<0.01$ level.

Table 5. Comparison of changes in STEM interest-related factors by STEM Interest Profile between 11/12 (sixth grade) and 12/13-year-old (seventh grade) youth

\begin{tabular}{|c|c|c|c|c|c|c|c|}
\hline \multirow{2}{*}{ STEM Interest Factors } & \multicolumn{2}{|c|}{$11 / 12$ yr old } & \multicolumn{2}{|c|}{$12 / 13$ yr old } & \multirow{2}{*}{$t$-value } & \multirow{2}{*}{$p$-value } & \multirow{2}{*}{ Cohen's $d$} \\
\hline & Mean & SE & Mean & SE & & & \\
\hline \multicolumn{8}{|l|}{ Science self-concept (negative) ${ }^{1}$} \\
\hline STEM Interested & 2.67 & 0.17 & 2.60 & 0.18 & 0.38 & 0.706 & 0.07 \\
\hline Math Disinterested & 2.96 & 0.14 & 3.11 & 0.16 & 0.93 & 0.356 & 0.15 \\
\hline STEM Disinterested & 2.67 & 0.23 & 3.13 & 0.22 & 2.16 & 0.040 & 0.40 \\
\hline \multicolumn{8}{|l|}{ Parent science attitude ${ }^{1}$} \\
\hline STEM Interested & 3.70 & 0.24 & 3.45 & 0.19 & 0.97 & 0.341 & 0.20 \\
\hline Math Disinterested & 2.97 & 0.19 & 2.94 & 0.16 & 0.15 & 0.883 & 0.02 \\
\hline STEM Disinterested & 3.00 & 0.22 & 2.47 & 0.16 & 2.61 & 0.015 & 0.55 \\
\hline \multicolumn{8}{|l|}{ STEM activities ${ }^{2}$} \\
\hline STEM Interested & 2.71 & 0.13 & 2.95 & 0.18 & 1.21 & 0.234 & 0.25 \\
\hline Math Disinterested & 2.39 & 0.10 & 2.27 & 0.12 & 1.55 & 0.127 & 0.16 \\
\hline STEM Disinterested & 2.10 & 0.16 & 2.06 & 0.14 & 0.34 & 0.738 & 0.05 \\
\hline \multicolumn{8}{|l|}{ Science aspirations ${ }^{1}$} \\
\hline STEM Interested & 2.41 & 0.23 & 2.61 & 0.24 & 0.85 & 0.401 & 0.15 \\
\hline Math Disinterested & 1.71 & 0.15 & 2.04 & 0.16 & 1.81 & 0.076 & 0.32 \\
\hline STEM Disinterested & 2.05 & 0.27 & 1.50 & 0.17 & 2.05 & 0.052 & 0.50 \\
\hline
\end{tabular}

Note: ${ }^{1}$ Items in index were coded on a five-point scale from $1={ }^{\prime}$ Disagree a lot' to $5={ }^{\prime}$ Agree a lot.' 2 Items were coded on a five-point scale from $1={ }^{\prime}$ Hardly ever or never' to $5={ }^{\prime}$ Almost every day.'

Previous research comparing boys and girls has reported significant gender differences with girls more often losing interest in STEM than boys during adolescence (e.g., Baram-Tsabari \& Yarden, 2008;
Frenzel et al., 2010). As described above, we did not find this pattern in the profiles where the majority of youth (both boys and girls) maintained at least a moderate interest in science, technology and engineering topics. 
However, when we examined interest changes for our sample as a whole, we found gender differences in STEM interest similar to those commonly reported in the literature with boys showing greater interest in technology/engineering at both time periods $(t=2.04$; $2.89, p=0.043 ; 0.004, d=0.36 ; 0.47)$ and girls becoming more interested in life science at age $12 / 13 \quad(t=2.89$, $p=0.004, d=0.47)$. In terms of interest pathways over the two years, girls' interest in life science and technology/engineering remained the same while their interest in earth/space science and math declined significantly. In contrast, boys only lost interest in life science (Table 4).

\section{DISCUSSION}

In this study of STEM interest development in youth, we examined STEM Interest Profiles and associated pathways between 11/12 and 12/13-year-olds in a lowincome urban community and explored factors that may have influenced the pathways. Our findings that youth on average lost interest in STEM over time would seem to support the commonly told story about the leaky STEM pipeline and the prevailing view that youth in urban communities do not like science or STEM because it is not relevant or interesting (Basu \& Barton, 2007). However, the cluster analysis in which we identified and compared STEM interested youth with those who were disinterested, indicated that this interpretation is incomplete because it does not adequately address the diversity in STEM interest within large groups of youth, including low-income youth. By segmenting youth based on their STEM interest profiles, we showed that the pathways of youth in the STEM Interested and Math Disinterested profiles did not exhibit the declining interest pattern that was seen for the cohort as a whole and that is commonly described in the literature. In fact, only youth in the STEM Disinterested profile reported the pattern of declining interest between ages 11/12 and $12 / 13$. In other words, for three quarters of youth, STEM interest remained the same or increased over time and the decline in STEM interest observed for youth as a whole was being driven by the significant declines in STEM interest of the $24 \%$ of youth in the STEM Disinterested profile.

These results suggest that declining STEM interest during adolescence may not be as widespread as commonly reported but may in part be an artefact of methodologies that do not adequately account for heterogeneity within sampled groups. Our findings indicated that most youth remained at least moderately interested in three STEM components and reinforced the assertions of practitioners, including those who work in urban, low-income communities, that many youth do indeed develop a sustained interest in STEM (Basu \& Barton, 2007; Brickhouse et al., 2000).
Our findings also challenged the prevailing story about gender and STEM. Although we found stereotypical STEM interest differences when we compared boys and girls (i.e., boys were more interested in technology whereas girls were more interested in life science), the cluster analysis revealed that while girls were more likely than boys to be clustered in the Math Disinterested profile, boys and girls were equally likely to be found in the STEM Interested and STEM Disinterested profile groups. In other words, by segmenting youth on the basis of STEM interest rather than gender, we found that there were as many STEM interested (and disinterested) girls as boys, a finding that was undetectable in the earlier comparison of STEM interest by gender. Our findings are in line with others who have reported that comparisons based on gender tend to exaggerate differences between the sexes while failing to recognize the diversity of interests within each group (Brickhouse et al., 2000).

These results suggest that educational interventions based on gender differences alone (except perhaps in the case of math) may be less effective than those that target the factors that appear to influence STEM interest development, regardless of gender. For example, STEM interested youth of both sexes were significantly more likely to believe that their parents had positive attitudes toward science and to participate in out-of-school STEM activities than youth who were disinterested in STEM. Therefore, it would seem that interventions that provide greater access to such activities or engage families in STEM may be more successful in supporting youth interest over time.

\section{Factors Affecting Persistence of STEM Interest}

Since most youth remained at least moderately interested in earth/space science, life science, and technology/engineering over time while youth in the STEM Interested profile actually reported an increase in technology/engineering interest, we examined factors that were associated with each profile to better understand this phenomenon. While others have found that school-related factors (e.g., classroom environment) were the strongest influence on STEM interest development and persistence (Myers \& Fouts, 1992; Osborne et al., 2003; Simpson \& Oliver, 1990; VedderWeiss \& Fortus, 2011), our data told a different story in which a variety of personal and environmental variables outside of school were the strongest predictors of persistent interest in STEM during adolescence. For example, youth who maintained a high interest in STEM between sixth and seventh grade also maintained consistently higher levels of science enjoyment, knowledge and relevance than disinterested youth. These factors are important indicators of the development of well-developed individual interests as opposed to more transient situational interests, suggesting that this group of youth will likely remain 
interested in STEM well into the future (Hidi \& Renninger, 2006; Renninger \& Hidi, 2016). In addition, these youth reported significantly more frequent participation in out-of-school STEM activities and more positive parental attitudes toward science over both years of the study than youth who disliked STEM. These findings reinforce those reported from studies of attitudes toward science in which parental support and attitudes to science (Breakwell \& Beardsell, 1992; Simpkins, Price, \& Garcia, 2015; Simpson \& Oliver, 1990) and youth participation in extra-curricular science activities (NRC, 2015) were strongly correlated with more positive attitudes toward science.

\section{Factors Affecting Declining STEM Interest}

While we are beginning to understand the factors that lead to the development and persistence of STEM interest over time, little is known of the factors that explain the widely reported decline in STEM interest for many adolescent youth (Potvin \& Hasni, 2014). In this cohort, only youth in the STEM Disinterested profile exhibited this pattern of declining interest over time. Although others have attributed these declines to schoolrelated factors such as quality of instruction in STEM courses (Myers \& Fouts, 1992; Vedder-Weiss \& Fortus, 2011), our findings indicated that decreases in STEM interest were associated with declines in science selfconcept, science enjoyment, and perceived parental attitudes toward science.

The relationship of declining science self-concept with declining STEM interest was particularly noteworthy because science self-concept did not differ among youth in the three STEM interest profiles at age $12 / 13$. However, only youth in the STEM Disinterested group evidenced significant declines in science selfconcept between ages 11/12 and 12/13. Previous research has indicated that perceived difficulty is an important influence on interest and/or subject choice (Havard, 1996; Krapp, 2007) so, the significant decline in science self-concept reported by disinterested youth may have been a contributing factor to their declining STEM interest relative to their peers.

The importance of parents in the generation and persistence of STEM attitudes or interest over time has been shown previously (e.g., Harackiewicz et al., 2012; Maltese et al., 2014; Thomas \& Strunk, 2017), but our study is the first to illuminate the role parents may have in explaining declining STEM interest over time. That is, youth who became disinterested in STEM between sixth and seventh grade also reported significant declines in their perceptions of their parents' attitudes toward science. These findings suggest the importance of understanding the changing relationship between youth and parents at this age because parental support and encouragement in STEM have the potential to be an important strategy for keeping more adolescents interested and engaged with STEM during the middle school years.

\section{Future Aspirations}

It is becoming increasingly clear that youth persistence in STEM is significantly related to affective and socioemotional factors such as identity, interest, and motivation which are stronger predictors of future engagement in STEM than achievement measured with grades and standardized test scores (Fortus, 2014; Maltese, Meilki, \& Wiebke, 2014; Maltese \& Tai, 2011; Vedder-Weiss \& Fortus, 2011). In particular, STEM interest during adolescence is strongly related to college major selection (Maltese \& Tai, 2011), college degree attainment (Maltese \& Tai, 2010; Tai, Liu, Maltese, \& Fan, 2006), and career choice (Stets, Brenner, Burke, \& Serpe, 2017; Venville, Rennie, Hanbury, \& Longnecker, 2013) suggesting that STEM Interested youth should exhibit more positive science aspirations than STEM disinterested youth. While it was true that youth who were interested in STEM also reported greater science aspirations than those in other profiles, the survey findings showed that on average they did not agree with the statement "I expect to become a scientist someday." This disconnect between interest in science topics or activities and future aspirations amongst low income and minority youth has been documented by others (e.g. DeWitt et al., 2011) and may have serious consequences with respect to future school and career choices due to the significant link between early aspirations and later educational and career choices (Beal \& Crockett, 2010; Tai et al., 2006). However, since this result may have been due in part to the wording of the question that may have been interpreted differently by different youth, we plan to revise the question in the future to better capture youth aspirations in science.

\section{CONCLUSIONS AND LIMITATIONS}

While some of our findings reinforced the existing understandings about STEM interest development during adolescence, our story differs in significant ways that help expand the narrative and inform the development of effective strategies for better supporting youth STEM interest. In particular, we question the use of methodologies that examine large groups of youth as homogeneous entities or that impose a priori grouping categories (e.g., gender) that do not address the diversity within these groups. We need to move beyond studies that simply document associations with demographic variables if we are to gain a more nuanced understanding of STEM interest and how and why it varies within and across communities of youth (Lee, 2008).

By segmenting youth based on interest, we were able to examine the differences between youth who remained interested in STEM or lost interest over time, regardless 
of gender or other arbitrary classifications. However, because our sample sizes were small and our findings potentially unique to the one metropolitan community we sampled, we acknowledge that our results may not be widely generalizable and that specific STEM interest patterns may differ for other populations. Nevertheless, we argue that our methods are generalizable and could be used in other locations to examine STEM interest profiles and pathways among large groups of youth, and what factors may affect these patterns.

Like many similar studies over the years, a major goal of the Synergies project is to develop research-based strategies for supporting youth STEM interest in our target community that could also potentially be used in other communities. In highlighting the significance of out-of-school factors, our study adds to the growing body of evidence for undertaking an ecosystem approach to STEM education in order to provide better support for STEM learning by being responsive to youths' interest and experience, and better connecting formal and informal STEM education experiences (NRC, 2015; Traphagen \& Traill, 2014). In particular, our findings support the development of out-of-school programs that align with youth STEM interests and the inclusion of parents as important allies in the STEM learning ecosystem.

\section{ACKNOWLEDGEMENTS}

This study was supported by generous funding from the Noyce Foundation.

\section{REFERENCES}

Andersen, L., \& Chen, J. (2016). Do high-ability students disidentify with science? A descriptive study of U.S. ninth graders in 2009. Science Education, 100(1), 57-77. https:/ / doi.org/10.1002/ sce.21197

Archer, L., DeWitt, J., Osborne, J., Dillon, J., Willis, B., \& Wong, B. (2012). Science aspirations, capital, and family habitus: How families shape children's engagement and identification with science. American Educational Research Journal, 49(5), 881908. https:/ / doi.org/10.3102/0002831211433290

Baram-Tsabari, A., \& Yarden, A. (2008). Girls' biology, boys' physics: Evidence from free-choice science learning settings. Research in Science \& Technological Education, 26(1), 75-92. https://doi.org/10.1080/ 02635140701847538

Barron, B. (2006). Interest and self-sustained learning as catalysts of development: A learning ecology perspective. Human Development, 49(4), 153-224. https:/ / doi.org/10.1159/000094368

Basu, S. J., \& Barton, A. C. (2007). Developing a sustained interest in science among urban minority youth. Journal of Research in Science Teaching, 44(3), 466-489. https://doi.org/10.1002/tea.20143
Beal, S. J., \& Crockett, L. J. (2010). Adolescents' occupational and educational aspirations and expectations: Links to high school activities and adult educational attainment. Developmental Psychology, 46(1), 258-265. https://doi.org/ $10.1037 / \mathrm{a} 0017416$

Bevan, B., Dillon, J., Hein, G. E., Macdonald, M., Michalchik, V., Miller, D., ... Yoon, S. (2010). Making science matter: Collaborations between informal science education organizations and schools. Washington, D.C.: Center for Advancement of Informal Science Education.

Breakwell, G. M., \& Beardsell, S. (1992). Gender, parental and peer influences upon science attitudes and activities. Public Understanding of Science, 1, 183-197. https:/ / doi.org/10.1088/0963-6625/1/2/003

Brickhouse, N. W., Lowery, P., \& Schultz, K. (2000). What kind of a girl does science? The construction of school science identities. Journal of Research in Science Teaching, 37(5), 441-458. https://doi.org/ 10.1002/(SICI)1098-2736(200005)37:5<441::AIDTEA4>3.0.CO;2-3

Burke, L., Francis, K., \& Shanahan, M. (2014). A horizon of possibilities: a definition of STEM education. Paper presented at the STEM 2014 Conference, Vancouver, July 12-15.

Campbell, G., Denes, R., \& Morrison, C. (Eds.). (2000). Access denied: Race, ethnicity, and the scientific enterprise. Oxford, England: Oxford University Press.

Chow, A., Eccles, J., \& Salmela-Aro, K. (2012). Task value profiles across subjects and aspirations to physical and IT-related sciences in the United States and Finland. Developmental Psychology, 48(6), 1612-1628. https:// doi.org/10.1037/a0030194

DeWitt, J., Archer, L., Osborne, J., Dillon, J., Willis, B., \& Wong, B. (2011). High aspirations but low progression: The science aspirations careers paradox amongst minority ethnic students. International Journal of Science and Mathematics Education, 9, 243-271. https://doi.org/10.1007/ s10763-010-9245-0

DeWitt, J., Osborne, J., Archer, L., Dillon, J., Willis, B., \& Wong, B. (2013). Young children's aspirations in science: The unequivocal, the uncertain and the unthinkable. International Journal of Science Education, 35(6), 1037-1063. https://doi.org/ 10.1080/09500693.2011.608197

Dunst, C. J., \& Raab, M. (2006). Influence of child interests on variations in child behavior and functioning. Ashville, NC: Winterberry.

English, L. D. (2016). STEM education K-12: Perspectives on integration. International Journal of STEM Education, 3(1). https://doi.org/10.1186/s40594016-0036-1 
Falk, J. H. \& Dierking, L. D. (2002) Lessons without limit: how free-choice learning is transforming education. Walnut Creek, CA: AltaMira Press.

Falk, J. H., \& Dierking, L. D. (2010). The 95\% Solution: School is not where most Americans learn most of their science. American Scientist, 98, 486-493. https://doi.org/10.1511/2010.87.486

Falk, J. H., \& Needham, M. D. (2013). Factors contributing to adult knowledge of science and technology. Journal of Research in Science Teaching, 50(4), 431-452. https:/ / doi.org/10.1002/tea.21080

Falk, J. H., Staus, N. L., Dierking, L. D., Penuel, W., Wyld, J., \& Bailey, D. (2016). Understanding youth STEM interest pathways within a single community: the Synergies project. International Journal of Science Education, Part B, 11, 195-212. https://doi.org/ 10.1080/21548455.2015.1093670

Ferry, T. R., Fouad, N. A., \& Smith, P. L. (2000). The role of family context in a social cognitive model for career-related choice behavior: A math and science perspective. Journal of Vocational Behavior, 57(3), 348-364. https:/ / doi.org/10.1006/jvbe.1999.1743

Fortus, D. (2104). Attending to affect. Journal of Research in Science Teaching, 51(7), 821-835. https://doi.org/10.1002/tea.21155

Fouts, J. T. (1987). High school social studies classroom environments and attitudes: A cluster analysis approach. Theory and Research in Social Education, 15(2), 105-114. https://doi.org/10.1080/00933104. 1987.10505540

Frenzel, A. C., Goetz, T., Pekrun, R., \& Watt, H. M. G. (2010). Development of mathematics interest in adolescence: Influences of gender, family, and school context. Journal of Research on Adolescence, 20(2), 507-537. https://doi.org/10.1111/j.15327795.2010.00645.x

Galton, M. (2009). Moving to secondary school: Initial encounters and their effects. Perspectives on Education (Primary Secondary Transfer in Science), 2, 5-21.

Gerard, R. W. (1957). Units and concepts of biology. Science, 125, 429-433. https://doi.org/10.1126/ science.125.3245.429

Gilmartin, S. K., Li, E., \& Aschbacher, F. (2006). The relationship between secondary students' interest in physical science or engineering, science class experiences, and family contexts: Variations by gender and race/ethnicity. Journal of Women and Minorities in Science and Engineering, 12(2-3), 179. 207. https://doi.org/10.1615/JwomenMinorScien Eng.v12.i2-3.50

Häussler, P., \& Hoffmann, L. (2002). An intervention study to enhance girls' interest, self-concept, and achievement in physics classes. Journal of Research in
Science Teaching, 39(9), 870-888. https://doi.org/ 10.1002/ tea.10048

Harackiewicz, J. M., Rozek, C. S., Hulleman, C. S., \& Hyde, J. S. (2012). Helping parents to motivate adolescents in mathematics and science: An experimental test of a utility-value intervention. Psychological Science, 23(8), 899-906. https:/ / doi.org /10.1177/0956797611435530

Havard, N. (1996). Student attitudes to studying A-level science. Public Understanding of Science 5(4), 321-330. https://doi.org/10.1088/0963-6625/5/4/002

Hidi, S., \& Renninger, K. A. (2006). The four-phase model of interest development. Educational Psychologist, 41, 111-127. https:/ / doi.org/10.1207/ s15326985ep4102_4

Jain, A., \& Dubes, R. (1988). Algorithms for clustering data. Englewood Cliffs: Prentice Hall.

Kodinariya, T. M., \& Makwana, P. R. (2013). Review on determining number of clusters in K-means clustering. International Journal of Advance Research in Computer Science and Management Studies, 1(6), 9095.

Krapp, A. (2002). An educational-psychological theory of interest and its relation to self-determination theory. In E. Deci \& R. Ryan (Eds.), The handbook of self-determination research (pp. 405-427). Rochester, NY: University of Rochester Press.

Krapp, A. (2007). An educational-psychological conceptualization of interest. International Journal of Educational and Vocational Guidance, 7, 5-21. https:/ / doi.org/10.1007/s10775-007-9113-9

Krapp, A., \& Prenzel, M. (2011). Research on interest in science: Theories, methods, and findings. International Journal of Science Education, 33(1), $27-$ 50. https://doi.org/10.1080/09500693.2010.518645

Krogh, L. B., \& Thomsen, P. V. (2005). Studying students' attitudes towards science from a cultural perspective but with a quantitative methodology: Border crossing into the physics classroom. International Journal of Science Education, 27(3), 281302. https://doi.org/10.1080/0950069041233131 4469

Lee, C. D. (2008). The centrality of culture to the scientific study of learning and development: How an ecological framework in education research facilitates civic responsibility. Educational Researcher, 37(5), 267-279. https://doi.org/ 10.3102/0013189X08322683

Lindahl, B. (2007, April). A longitudinal study of students' attitudes towards science and choice of career. Paper presented at the meeting of NARST, New Orleans, LA.

Maltese, A. V., Melki, C. S., \& Wiebke, H. L. (2014). The nature of experiences responsible for the generation 
and maintenance of interest in STEM. Science Education, 98, 937-962. https://doi.org/10.1002/ sce. 21132

Maltese, A. V., \& Tai, R. H. (2011). Pipeline persistence: Examining the association of educational experiences with earned degrees in STEM among U.S. students. Science Education, 95, 877-907. https://doi.org/10.1002/sce.20441

Moran, M. D. (2003). Arguments for rejecting the sequential Bonferroni in ecological studies. Oikos, 100(2), 403-405. https://doi.org/10.1034/j.16000706.2003.12010.x

Myers, R. E., \& Fouts, J. T. (1992). Cluster analysis of high school science classroom environments and attitude toward science. Journal of Research in Science Teaching, 29(9), 929-937. https://doi.org/10.1002/ tea.3660290904

National Research Council. (2011). Successful K-12 STEM education: Identifying effective approaches in science, technology, engineering, and mathematics. Washington, DC: National Academies Press.

National Research Council. (2015). Identifying and supporting productive STEM programs in out-of-school settings. Washington, DC: National Academies Press.

Ormerod, M., \& Duckworth, D. (1975). Pupils' attitudes to science. Slough: NFER.

Osborne, J., Simon, S., \& Collins, S. (2003). Attitudes toward science: A review of the literature and its implications. International Journal of Science education, 25(9), 1049-1079. https:/ / doi.org/10.1080 /0950069032000032199

Potvin, P., \& Hasni, A. (2014). Interest, motivation, and attitude towards science and technology at K-12 levels: A systematic review of 12 years of educational research. Studies in Science Education 50(1), 85-129. https://doi.org/10.1080/03057267. 2014.881626

Renninger, K. A., \& Hidi, S. (2011). Revisiting the conceptualization, measurement, and generation of interest. Educational Psychologist 46(3), 168-184. https:/ / doi.org/10.1080/00461520.2011.587723

Renninger, K. A. \& Hidi, S. E. (2016). The power of interest for motivation and engagement. New York: Routledge. https://doi.org/10.4324/9781315771 045

Renninger, K. A., \& Riley, K. R. (2013). Interest, cognition, and the case of L- and science. In S. Kreitler (Ed.). Cognition and motivation: Forging an interdisciplinary perspective (pp. 352-382), Cambridge: Cambridge University Press. https:// doi.org/10.1017/CBO9781139021463.021

Renninger, K. A., \& Su, S. (2012). Interest and its development. In R. Ryan (Ed.), The Oxford handbook of human motivation (pp. 167-187). New York:
Oxford University Press. https:/ / doi.org/10.1093/ oxfordhb/9780195399820.013.0011

Salta, K., \& Tzougraki, C. (2004). Attitudes toward chemistry among $11^{\text {th }}$ grade students in high schools in Greece. Science Education, 88(4), 535-547. https:// doi.org/10.1002/sce.10134

Schreiner, C., \& Sjøberg, S. (2004). Sowing the seeds of ROSE. Background, Rationale, Questionnaire Development and Data Collection for ROSE (The Relevance of Science Education) - a comparative study of students' views of science and science education (Acta Didactica 4/2004). Oslo: Dept. of Teacher Education and School Development, University of Oslo. Retrieved from www.ils.uio.no/english/rose

Sheldrake, R., Mujtaba, T., \& Reiss, M. J. (2019). Students' changing attitudes and aspirations towards physics during secondary school. Research in Science Education, 49, 1809-1834. https:/ / doi.org/10.1007/ s11165-017-9676-5

Simpkins, S. D., Price, C. D., \& Garcia, K. (2015). Parental support and high school students' motivation in biology, chemistry, and physics: Understanding differences among Latino and Caucasian boys and girls. Journal of Research in Science Teaching, 52(10), 1386-1407. https:/ / doi.org/10.1002/tea.21246

Simpson, R. D., \& Oliver, J. S. (1990). A summary of the major influences on attitude toward and achievement in science among adolescent students. Science Education, 74, 1-18. https://doi.org/ 10.1002 / sce. 3730740102

Sjøberg, S., \& Schreiner, C. (2010). The ROSE project. An overview and key findings. Retrieved from http:/ / roseproject.no/network/countries/norwa y/eng/nor-Sjoberg-Schreiner-overview-2010.pdf

Staus, N. L., Lesseig, K., Lamb, R., Falk, J. H., \& Dierking, L. (2019). Validation of a measure of STEM interest for adolescents. International Journal of Science and Mathematics Education. https://doi.org/10.1007/ s10763-019-09970-7

Stets, J. E., Brenner, P. S., Burke, P. J., \& Serpe, R. T. (2017). The science identity and entering a science occupation. Social Science Research, 64, 1-14. https:// doi.org/10.1016/j.ssresearch.2016.10.016

Stocklmayer, S.M., Rennie, L.J. \& Gilbert, J.K. (2010). The roles of the formal and informal sectors in the provision of effective science education. Studies in Science Education, 46 (1), 1-44. https://doi.org/ $10.1080 / 03057260903562284$

Tai, R. H., Liu, C. Q., Maltese, A. V., \& Fan, X. (2006). Planning early for careers in science. Science, 312, 1143-1144. https://doi.org/10.1126/science.1128 690

Taylor, P. (1993). Minority ethnic groups and gender access in higher education. New Community, 19, 425- 
440. https:// doi.org/10.1080/1369183X.1993.9976 375

Thomas, J. A., \& Strunk, K. K. (2017). Expectancy-value and children's science achievement: Parents matter. Journal of Research in Science Teaching, 54(6), 693-712. https://doi.org/10.1002/tea.21382

Traphagen, K., \& Traill, S. (2014). How cross-sector collaborations are advancing STEM learning. Los Altos, CA: Noyce Foundation.

U.S. Census Bureau. (2012). Current population survey, 2011 annual social and economic supplement. Washington, DC: Department of Labor.
Vedder-Weiss, D. \& Fortus, D. (2011). Adolescents' declining motivation to learn science: Inevitable or not? Journal of Research in Science Teaching, 48(2), 199-216. https:/ / doi.org/10.1002/tea.20398

Venville, G., Rennie, L., Hanbury, C., \& Longnecker, N. (2013). Scientists reflect on why they chose to study science. Research in Science Education, 43(6), 22072233. https:/ / doi.org/10.1007/s11165-013-9352-3

Wright, S. P. (1992). Adjusted p-values for simultaneous inference. Biometrics, 48, 1005-1013. https:/ / doi.org $/ 10.2307 / 2532694$

\section{APPENDIX}

Table A1. Items comprising survey components and corresponding Cronbach's alphas

Earth/space science interest (4 items) ${ }^{1}$ (sixth/seventh grade)

(What it is like on other planets and exploring space; How stars and planets form; Why clouds, rain, and weather happen; How earthquakes, volcanoes, and hurricanes happen)

Life science interest (3 items) ${ }^{1}$

(What to eat and how to exercise to keep healthy and fit; How traits are passed from parents to children; How the human body works)

Technology/engineering interest (5 items) ${ }^{1}$

(How buildings and bridges are made; How to use maps or GPS to find a place; How to design new games or toys; How gas and diesel engines work; How computers or cell phones work)

Mathematics interest $(4 \text { items })^{1}$

(How to do Sudoku or other math problems; How to measure the size or area of things; How to make different shapes and patterns out of stuff; How to solve puzzles)

Science enjoyment $(6 \text { items })^{2}$

(I enjoy learning science; I am pretty good at science; I learn things quickly in science; I like science; I find science to be really interesting; Science is boring ${ }^{3}$ )

Negative science self-concept ( 3 items) ${ }^{2}$ at science)

(I find science difficult; Science is harder for me than for other kids my age; I am just not good

Parental attitudes to science ( 2 items) ${ }^{2}$

(My parents are interested in science; My parents want me to be interested in science)

Science relevance (5 items) ${ }^{2}$

(Science will be useful in my future; I see how science relates to my life; Science is helpful in understanding today's world; My science teacher makes me interested; Science is useful in helping solve problems)

Note: ${ }^{1}$ Items were coded on a five-point scale from $1={ }^{\prime \prime}$ Dislike a lot" to $5={ }^{\prime \prime}$ Like a lot" in response to prompt "How much do you like finding out about"; 2 Items were coded on a five-point scale from 1="Strongly disagree" to 5="Strongly agree"; ${ }^{3}$ Item was reverse coded for analysis. Items in italics were used to construct the STEM knowledge and STEM support indexes.

\section{http://www.ejmste.com}

